\title{
A urbanidade do novo rural: loteamento dos espaços e privatização da paisagem no brejo paraibano
}

O brejo paraibano é uma das vinte e três microrregiões do estado. Determinadamente, recebeu essa nomenclatura devida a paisagem que reúne altos topográficos de serras e morros

O brejo paraibano é uma das vinte e três micro cobertos por florestas ombrófilas a estacionais. São regiões naturais de clima úmido e sub-úmido, que fazem parte da diversidade biológica da Mata Atlântica, mas insularizados pelo Semiárido e Cerrado, encontradas nos estados do Ceará, Rio Grande do Norte, Paraíba e Pernambuco. Diante disso, a inclusão dos condomínios de alto padrão (horizontas e verticais) em áreas rurais e perurbanas dos municípios de Areia e Bananeiras necessita ser investigada, uma vez que tem denotado uma mudança de função no espaço rural em detrimento do loteamento dos espaços a sociedades alóctones, desencadeando transformações socioespaciais e privatização dos componentes da paisagem. Nesse contexto, a presente pesquisa busca espacializar e discutir essas mudanças da forma de uso do espaço rural (tradicionalmente bucólico agrário) e o incremento de urbanidades, principalmente quando esse passou a ser tratado enquanto mercadoria imobiliária e atrativo turístico, postulados por uma intensa valoração e valorização a consumidores com alto poder aquisitivo. Apesar de privativo em seu interior, com cobranças de taxas e impostos de uso dos serviços oferecidos, esses empreendimentos, ao se instalarem, necessitam da prestação de serviços públicos, como coleta de resíduos, transporte público, pavimentação e a aumento expresivo da viôn ế O aumento expresivo da vion,

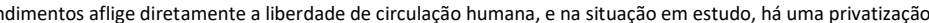
dos elementos da paisagem, como a água, assim como destruição de APPs.

Palavras-chave: Novo rural; Capital imobiliário; Condomínios.

\section{The urbanity of the new rural: allotment of spaces and privatization of the landscape in the parabian marsh} and hills covered by ombrophylous and seasonal forests. They are natural regions of humid and sub-humid climate, which are part of the biological diversity of the Atlantic Forest, but insularized by the Semiarid and Cerrado, found in the states of Ceará, Rio Grande do Norte, Paraíba and Pernambuco. In view of this, the inclusion of the high-standard condominium (horizontal and vertical) in rural and perurban areas of the municipalities of Areia and Bananeiras needs to be investigated, since it has denoted a change of function in the rural space to the detriment of the allotment of spaces to societies allochthons, triggering socio-spatial transformations and privatization of landscape components. In this context, the present research seeks to spatialize and discuss these changes in the way of use of rural space (traditionally bucolic agrarian) and the increase of urbanities, especially when it came to be treated as a real estate commodity and tourist attraction, postulated by an intense valuation and es have any type of influence under the expressive increase of the violence and rural exodus of the municipalities, which directly jeopardize the primary sector. In addition to the land subdivision law, closed condominiums are based on Federal Law No. 4,591 / 1964. However, the conjuncture of these developments directly afflicts the freedom of human movement, and in the situation under study, there is a privatization of landscape elements, such as water, as well as destruction of PPAs.

Keywords: New rural; Real estate capital; Condominiums.

Topic: Geomorfologia

Reviewed anonymously in the process of blind peer.

Ailson de Lima Marques

Universidade Federal da Paraíba, Brasil

http://lattes.cnpq.br/7731519684534647

marques.ailsonl@gmail.com

Jose Kennedy do Nascimento Ribeiro

Universidade Federal da Paraíba, Brasil

http://lattes.cnpq.br/0509502439867132

kennedy ribeiro@hotmail.com

Ewerton da Silva Barbosa

Universidade Federal da Paraíba, Brasil

http://lattes.cnpq.br/9038746208521577

ewertonbarbosa@hotmail.com
Received: 14/08/2017

Approved: 06/11/2017
Referencing this:

MARQUES, A. L.; RIBEIRO, J. K. N.; BARBOSA, E. S.. A urbanidade do novo rural: loteamento dos espaços e privatização da paisagem no brejo paraibano. Nature and Conservation, v.10, n.2, p.15-24, 2017. DOI: http://doi.org/10.6008/SPC2318-2881.2017.002.0002 


\section{INTRODUÇÃO}

O meio rural tem passado por grandes transformações que vem abrangendo relações de produção e trabalho, comércio e habitacionais, decorrentes do processo de intensificação da globalização e modernização das atividades do campo. As atividades essencialmente agrárias vêm enfrentando problemas, como a desagregação das formas tradicionais de articulação da produção e uma desvalorização gradativa em função da introdução de tendências atuais e mercados consumidores específicos, que tem estruturado a urbanidade no campo, através da dinamização do mercado imobiliário.

A interpretação sobre o fenômeno urbano-rural na fase pós-industrial do capitalismo está fortemente imbricada na abordagem dos enclaves residenciais, denominados comumente "condomínios horizontais". Porém, nas últimas décadas, o mercado imobiliário tem reproduzido e conferido "novas" simbologias à apropriação de terras, como tem acontecido especificamente em áreas rurais e periurbanas através da instalação de núcleos urbanos de alto padrão na zona rural, introduzindo o marketing de áreas verdes em muitas regiões do Brasil, e que no Brejo paraibano está condicionando uma mudança econômica de função.

Diante disso, a inclusão dos condomínios de alto padrão em áreas rurais e perurbanas dos municípios de Areia e Bananeiras necessita ser investigada, uma vez que se tem denotado uma mudança de função no espaço rural em detrimento do loteamento dos espaços a sociedades alóctones, desencadeando transformações socioespaciais e privatização dos componentes da paisagem. A presente pesquisa busca espacializar e discutir essas mudanças da forma de uso do espaço rural, tradicionalmente bucólico agrário, e o incremento de urbanidades, principalmente, quando esse passou a ser tratado enquanto mercadoria imobiliária e atrativo turístico, postulados por uma intensa valoração e valorização à consumidores com alto poder aquisitivo.

\section{REVISÃO TEÓRICA}

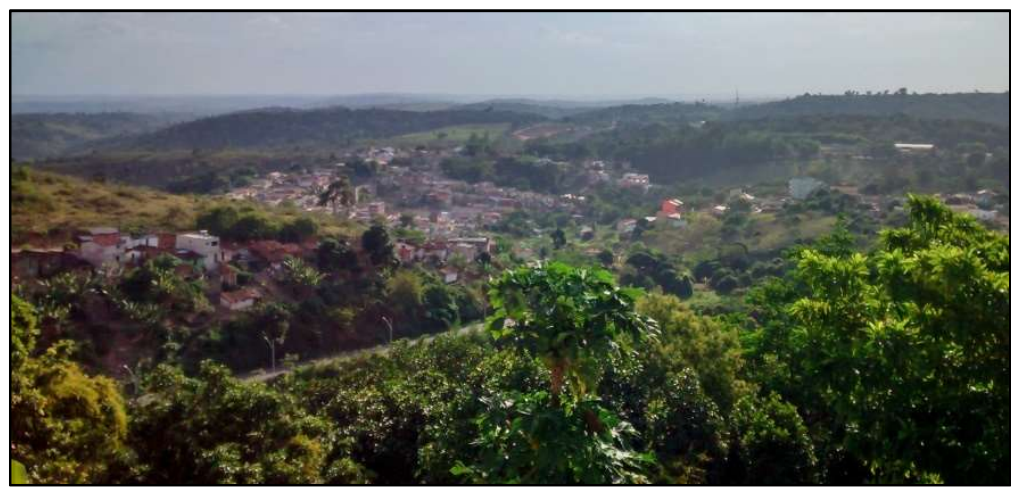

Figura 1: Aspectos do brejo paraibano no município de Areia.

O brejo paraibano é uma das vinte e três microrregiões do estado. Determinadamente recebeu essa nomenclatura devida a paisagem que reúne altos topográficos de serras e morros cobertos por florestas ombrófilas a estacionais. São regiões naturais de clima úmido e sub-úmido que fazem parte da diversidade biológica da Mata Atlântica, mas insularizados pelo Semiárido e Cerrado, encontradas nos estados do Ceará, 
Rio Grande do Norte, Paraíba e Pernambuco. A existência desses ambientes na zona oriental do Nordeste, conforme se nota na figura 1, está associada à ocorrência do Planalto da Borborema (ARAÚJO, 2012; TABARELLI et. al., 2004;).

\section{O (novo) rural brasileiro e a urbanidade}

O brejo paraibano apresenta um contexto histórico agrário ligado essencialmente aos ciclos da cana de açúcar e do café, que deixaram um legado histórico, arquitetônico e turístico. A cidade de Areia é Patrimônio Cultural do Brasil, tombada pelo Instituto do Patrimônio Histórico e Artístico Nacional (IPHAN) em 2006; e Bananeiras é Patrimônio Histórico da Paraíba, tombada pelo Instituto do Patrimônio Histórico e Artístico do Estado da Paraíba em 2010.

Alguns engenhos remanescentes do ápice do ciclo da cana de açúcar na região, além de produzir derivados da cana de açúcar incorporaram o turismo rural. Segundo Brasil (2013) o Turismo Rural é o conjunto de atividades turísticas desenvolvidas no meio rural, comprometido com a produção agropecuária, agregando valor a produtos e serviços, resgatando e promovendo o patrimônio cultural e natural da comunidade; já nas pequenas propriedades é observável um processo crescente de êxodo rural ligado à violência no campo, o que tem despertado a atuação dos setores imobiliário e turístico, e dessa forma, o turismo de segunda residência intrinsicamente ligado a empreendedores alheios à sociedade autóctone. $\mathrm{O}$ turismo de segunda residência pode ser entendido e configurado na situação em discussão por meio de Becker (2003):

[...] no Brasil, o aparecimento do fenômeno da segunda residência dá-se na década de 1950 sob a égide do "nacional-desenvolvimentismo", que foi responsável pela implantação da indústria automobilística, pela ascensão do rodoviarismo como matriz principal dos transportes e pela emergência de novos estratos sociais médios e urbanos que, aos poucos, começariam a incorporar, entre os seus valores sócio-culturais, a ideologia do turismo e do lazer. O veraneio ou o descanso dos fins de semana se transformaram em valor social cuja satisfação levaria o turismo, de um modo muitas vezes predatório e desordenado, a regiões acessíveis a grandes centros urbanos [...], e com atributos valorizados (zonas costeiras e/ou serranas).

Assim, o abandono da terra por êxodo rural, a especulação imobiliária, e a supervalorização decorrente do turismo de segunda residência têm ocasionado uma mudança de função no espaço rural no brejo paraibano. Antes, um espaço rural, essencialmente agrário; hoje, um ambiente do setor imobiliário de alto padrão. Esse processo é compreendido como "Novo Rural Brasileiro". No que chamou "Novo Rural Brasileiro", Silva (1999), expõe as várias modificações que estão acontecendo no Brasil, que ressaltam a apropriação do espaço rural e a imposição de modificações a ele, para se adequar à sociedade em suas necessidades de auto segregação urbanística, lazer, habitação e segurança.

Ser urbano hoje não deve ser interpretado pela lógica de viver no perímetro urbano. Esse entendimento da apropriação da paisagem (paisagem pura) pela sociedade urbana com fins habitacionais também é discutido por Botelho (2007), quando o autor trata da natureza pura com valor de troca e de mercado, assim: 
Estranhamente, o direito à natureza (ao campo e à "natureza pura") faz parte dos hábitos sociais há já alguns anos graças ao lazer. Fez o seu percurso através do vitupério que se tornou banal contra o barulho, a fadiga e o universo "concentracionário" das cidades (quando a cidade apodrece ou explode). Percurso estranho, dizemos nós: a natureza aparece no valor de troca e de mercado; compra-se e vende-se. O lazer comercializado, industrializado, organizado institucionalmente, destrói está "naturalidade" de que nos apropriámos para poder negociá-la. A "natureza", ou aquilo que é pretensamente apresentado como tal, o que dela subsiste, torna-se o gueto do lazer, o lugar da fruição, o refúgio da "criatividade". Os urbanos transportam o urbano com eles, mesmo que não transportem a urbanidade.

Caldeira (2000), ao aprofundar a compreensão socioespacial dos condomínios habitacionais de alto padrão, denominou-os de "enclaves fortificados", uma vez que são delineados pela produção de espaços habitacionais, onde há uma infraestrutura urbana, de segurança, de lazer e de serviços caracterizados pelo privativo aos condôminos. Ainda segundo Caldeira (2000), são também "fisicamente demarcados e isolados por muros, grades, espaços vazios e detalhes arquitetônicos", estando "[...] voltados para o interior" em contraposição à rua e sendo. A violência dos grandes centros tem tido papel importante na expansão desses ambientes segregados. Segundo Santos (2015):

Face à violência real e percebida em cidades grandes, planejadores e autoridades têm sido cada vez mais confrontados com o desejo dos citadinos de limitar, segmentar e separar os espaços em nome da segurança. Os condomínios fechados, bem como a segurança dos centros comerciais por empresas de segurança, também é um reflexo da desconfiança em relação à capacidade das autoridades públicas em garantir a segurança de bens e pessoas. Essa desconfiança é demonstrada por meio dos empreendimentos fechados e seguros, que se multiplicam em países em desenvolvimento, onde os proprietários preferem usar serviços privados para garantir a sua segurança, como na Argentina ou no Brasil.

Para Sogame (2001): “Os lugares segregados da cidade moderna não são justapostos. São hierárquicos e representam espacialmente essa hierarquia voltada a condicionantes econômicas e sociais". Deve-se salientar o fato de que, além dos muros visíveis que separam esses grupos dos de fora, acrescentamse os muros internos invisíveis, que se referem ao processo sempre mutável de apropriação de marcas e poder (ALVES FILHO, 2001), e características como governança privada e a garantia de exclusividade do lugar. O professor de Arquitetura e Urbanismo, Fábio Duarte, em entrevista à revista de arquitetura aU, em 2011, destacou que:

Os condomínios fechados são uma reação à insegurança urbana, embrulhados em discursos de bairros ecológicos ou bairros-clubes. Quando dentro das cidades, eles criam ilhas de convivência controlada, que privatizam e rompem o tecido urbano, e impedem o contato cotidiano com a diversidade social, econômica e cultural, própria das cidades. Quando nos municípios adjacentes aos grandes centros, são como parasitas: seus moradores pagam o IPTU das cidades periféricas, mas não as vivem, pois seus filhos vão à escola na cidade-polo, onde também fazem compras e trabalham. O plano diretor é o instrumento legal para impedir esse tipo de ocupação urbana. Nas cidades do interior, onde o fenômeno é crescente, mas recente, arquitetos e urbanistas podem ter dois papéis: buscar influenciar politicamente as decisões municipais, incluindo alterações no plano diretor que impeçam esses condomínios; ou mostrar que há alternativas de desenho urbano para bairros que não constituam ilhas isoladas da cidade.

A esse fenômeno de se refugiar em ambientes que oferecem condições privativas de segurança, como vigilância 24h, muros, cercas elétricas, sensores e câmeras, Nasser (2014) denomina de "militarização do espaço urbano", que decorre do aumento expressivo da população urbana, da violência e do crime organizado nas cidades nos últimos 20 anos. Segundo Nasser (2014): 
Esta realidade urbana tem implicações econômicas e políticas enormes e é repleta de problemas, que vão das necessidades de transportes, água, saúde, eletricidade e habitação às questões relacionadas ao tráfico de drogas e à criminalidade. A dimensão das cidades como espaço de uso da violência foi mais intensamente realçada pelos meios de comunicação nos países desenvolvidos a partir dos atentados terroristas ocorridos no dia 11 de setembro de 2001 nos Estados Unidos, bem como, posteriormente, em solo europeu (Madri e Londres) [...]. Como tal, a globalização está transformando o ambiente de segurança internacional, estimulando mudanças na utilização dos recursos, da infraestrutura e das capacidades disponíveis, facilitando a mobilização política transnacional dos atores não estatais".

Diante disso, a inclusão dos condomínios de alto padrão em áreas rurais e perurbanas de forma desenfreada, nos brejos de altitude, necessita ser investigada, uma vez que tem denotado uma mudança de função no espaço rural em detrimento do loteamento dos espaços a sociedades alóctones, desencadeando transformações socioespaciais e privatização dos componentes da paisagem.

\section{MATERIAIS E MÉTODOS}

\section{Áreas de estudo}

As áreas em estudo compreendem os municípios de Areia e Bananeiras, como pode ser isto na figura 2, localizados no interior do estado da Paraíba, na mesorregião do agreste e microrregião do brejo. Areia apresenta uma área de $269,4 \mathrm{Km}^{2}$, uma população estimada em 23.829 .00 habitantes e uma densidade demográfica de 88,45 hab./ $\mathrm{Km}^{2}$. Já Bananeiras, uma área de $257,931 \mathrm{Km}^{2}$, uma população estimada em 21.276.00 habitantes e uma densidade demográfica de 84,72 hab./ $\mathrm{km}^{2}$ (IBGE, 2015).

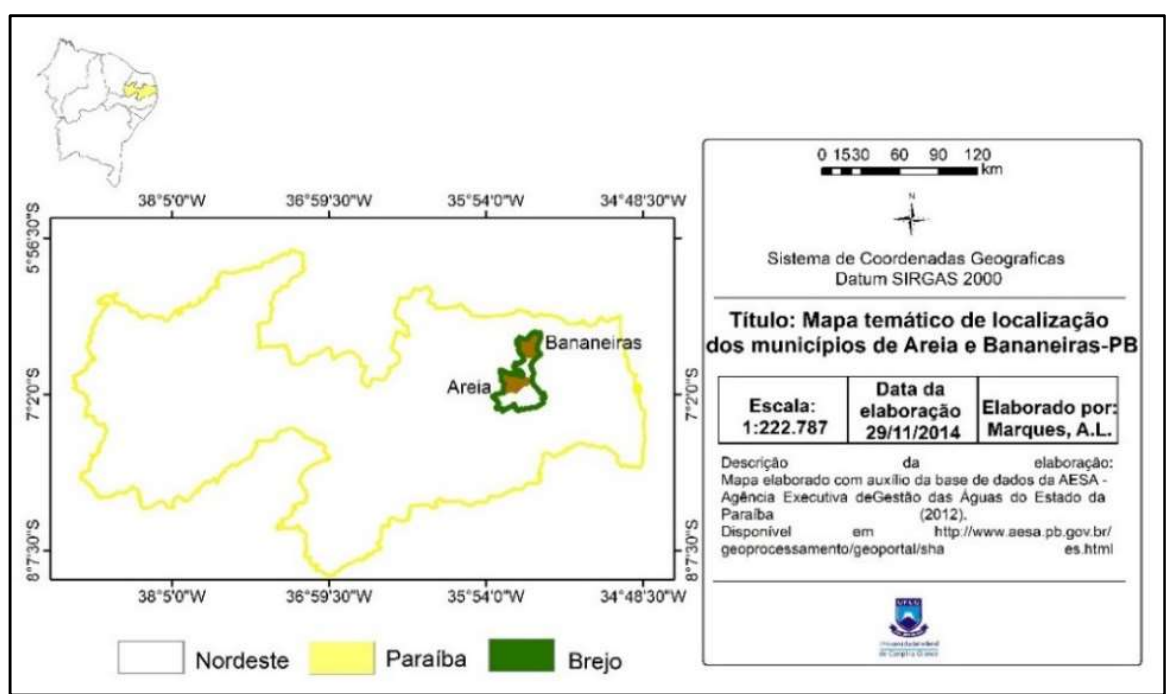

Figura 2: Mapa temático de localização de abrangência da pesquisa. Fonte: IBGE (2015).

\section{Etapas procedimentais}

Nas análises documental e midiática, foram consultados os sites das prefeituras a fim de identificar políticas públicas de incentivo fiscal ou outras que tenham como foco empreendedores imobiliários; foram visitados os sites dos empreendimentos para análise da mídia (fotos, mapas e/ou campanhas publicitárias). Já no segundo momento, foi feita uma entrevista livre com um corretor de inoveis da área em estudo, que manteve seu anonimato, e aplicada uma análise de conteúdo baseada em Franco (2005), sendo também 
analisados os Planos Diretores municipais. As preguntas que fizeram parte da entrevista envolveram: quantificação dos empreendimentos nos dois municípios; estrutura empregada; tamanhos e valoração dos lotes; classes de foco e origem dos empreendedores e condôminos.

\section{RESULTADOS E DISCUSSÃO}

De acordo com o corretor entrevistado no município de Areia, há, ao menos, quatro condomínios; já no município de Bananeiras há, ao menos, seis condomínios. Conforme proposto nas figuras 3 e 4, tem-se imagens dos panfletos desses empreendimentos habitacionais nos municípios de Areia e Bananeiras-PB. São comercializados sob o marketing das áreas verdes, devido à localização em meio a resquícios florestais nas zonas rurais e periurbanas dos municípios. Notadamente em ambos os municípios alguns empreendimentos apresentam pousadas, clubes de golf, haras, hotéis, clubes aquáticos, restaurantes, entre outros serviços. Configurando-se assim, "empreendimentos híbridos".

Segundo estimativas imobiliárias, $0 \mathrm{~m}^{2}$ desses empreendimentos pode chegar a 250 reais; os lotes variam com custo de 150 a 250 mil reais, com ou sem as habitações. As habitações seguem padrões contratuais, onde prevalece a influência da arquitetura suíça. As classes sociais foco desses empreendimentos variam entre a Alta classe média (renda média familiar - RMF: R\$9.897,00), Baixa classe alta (RMF: $\mathrm{R} \$ 17.434,00)$ e Alta classe alta (RMF: acima de $\mathrm{R} \$ 20.000,00)$. A maioria dos empreendedores são oriundos de centros como João Pessoa-PB, Campina Grande-PB e Natal-RN, que fogem das turbulências e insegurança, se refugiando nessas residências secundarias, porém, sem perder a infraestrutura urbanística (muros, segurança, serviços privilegiados e etc). A ocupação atual dos lotes gira em torno de $70 \%$. Atuando como financeiras os bancos: Caixa Econômica Federal, Banco do Brasil, Bradesco e Itaú e incentivos do Programa Minha Casa Minha Vida.

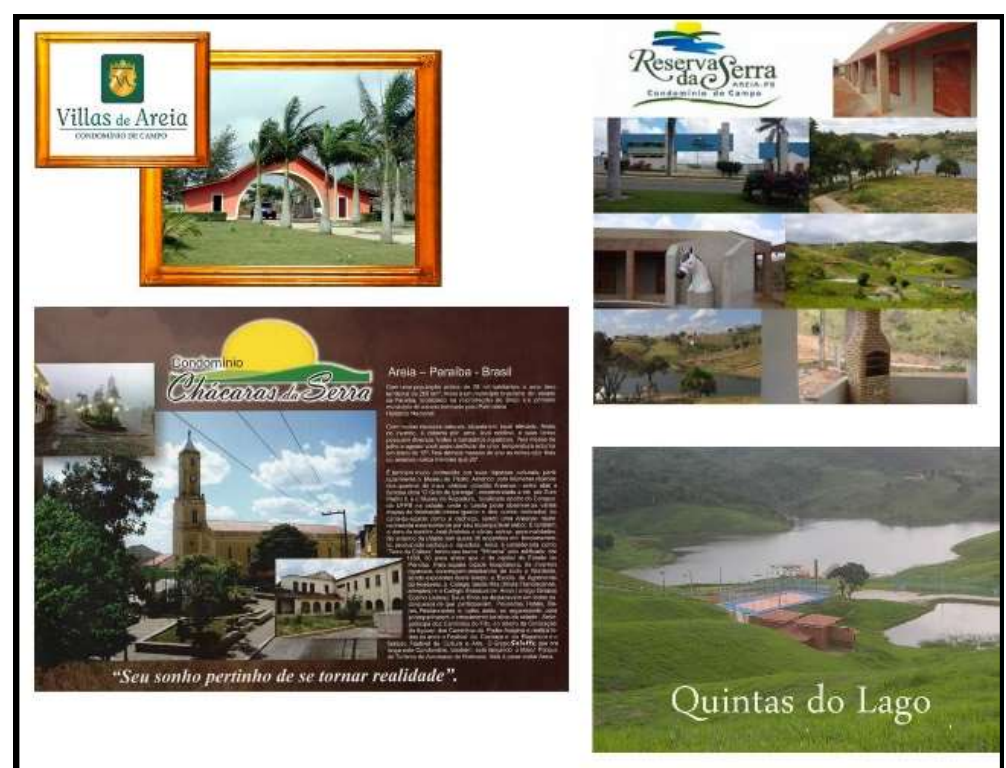

Figura 3: Imagens públicas dos condomínios no município de Areia-PB.

Entre as empresas que têm atuado nesse setor, está a LTL Construções e Incorporações, que iniciou sua expansão com os condomínios Caminho da Serra e 2006 (horizontal), Águas da Serra e o Serra Golf Apart 
Hotel em 2007 (horizontais), além do Alto da Serra Villas em 2016 (vertical), todos em Bananeiras. Em 2012 a empresa investiu em Areia, com o Condomínio Reserva da Serra (horizontal).

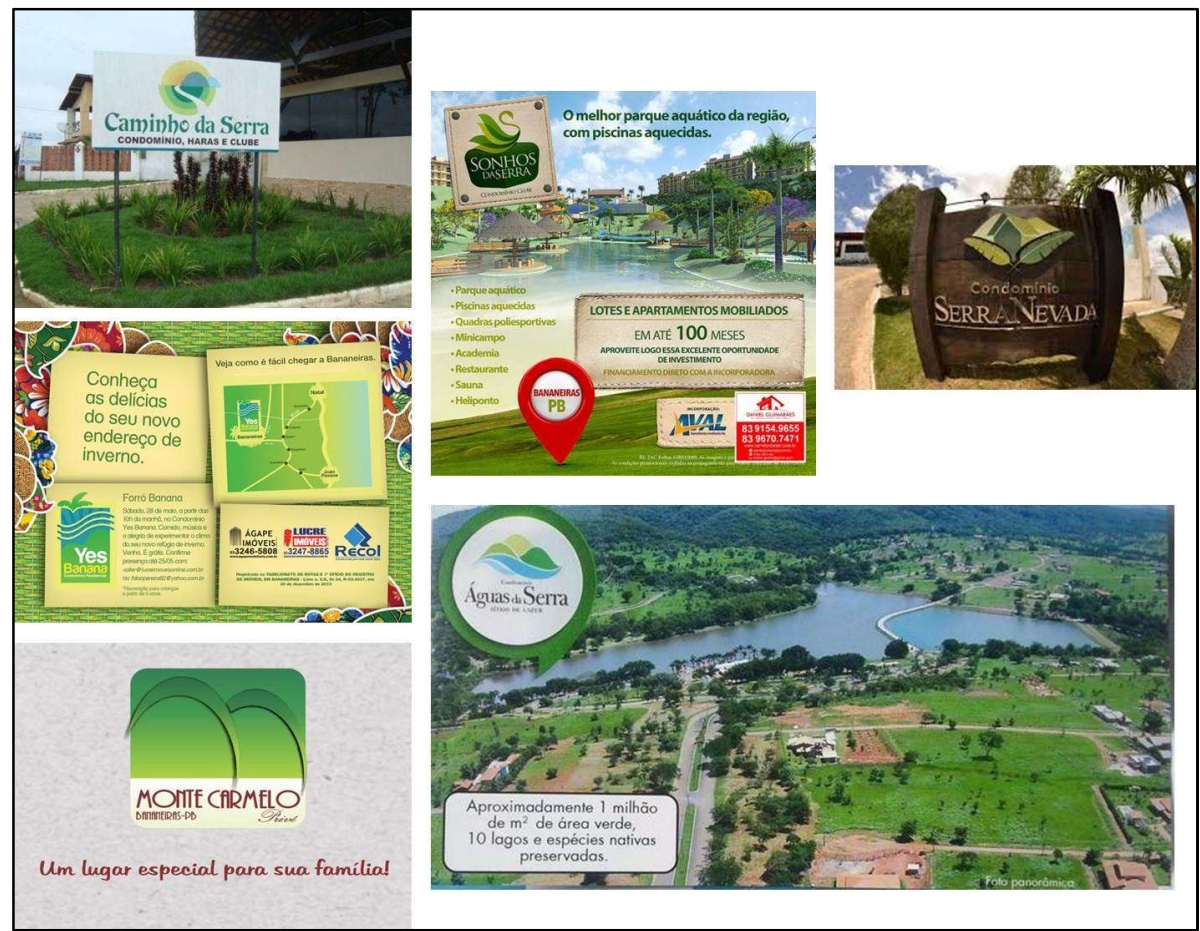

Figura 4: Imagens dos condomínios no município de Bananeiras-PB.

Na consulta aos Planos Diretores dos municípios em análise, foi verificado que não há tipicidade que aborde a criação e expansão desses empreendimentos na área rural. Especificamente no município de Areia, é verificável uma segregação socioespacial tendenciosamente ligada à privatização de bens públicos dispostos perifericamente aos empreendimentos, uma vez que os condomínios: Reserva da Serra, Chácaras da Serra e Quintas do Lago permeiam as margens do reservatório Saulo Maia, principal manancial do município.

Marques et al. (2013) e Araujo et al. $(2015 ; 2016)$ identificaram essa privatização das margens desse reservatório (patrimônio público) através da ocupação, uso e possível poluição do manancial por parte desses empreendimentos, fato esse é um descumprimento à Lei Federal no 12.651/2012 (Código Florestal), que prevê uma margem de mata ciliar com até 100m (Áreas de Preservação Permanentes - APPs). Há um descumprimento evidente ao Decreto № 24.643/1934 (Código de Águas), que garante o acesso comum de todos às fontes de água, assim como a desobstrução. Já no município de Bananeiras, alguns desses empreendimentos situam-se também na zona periurbana e apresentam ocupações irregulares na paisagem de instabilidade geomorfológica, além de deterioração da vegetação de encostas, que configura um negligenciamento da estabilização ambiental promovida pelas APPs urbanas (ARAUJO et al., 2015; 2016).

Em face dessa problemática, a Promotoria de Justiça do Meio Ambiente do Ministério Público da Paraíba (MPPB) no município de Bananeiras em 2013, proferiu liminar e agravo em ação cautelar preparatória de ação civil pública contra a empresa LTL Construções e Incorporações Ltda., a 
Superintendência de Administração do Meio Ambiente (SUDEMA) e a prefeitura de Bananeiras. De acordo com a ação:

[...] a empresa LTL estaria construindo um empreendimento imobiliário composto de um centro comercial (shopping) e um condomínio residencial vertical numa encosta extremamente íngreme localizada entre Bananeiras e Solânea sem a realização do estudo prévio de impacto ambiental, conforme determina a Lei Complementar 140, de 2011, e das Leis Federais 12.305/10, 12.651/12 e 6938/81. [...] Ao prefeito de Bananeiras [...] foi expedida uma recomendação para que a prefeitura exija o estudo de impacto de vizinhança a ser realizado por equipe particular, conforme é previsto na Lei 10.257/01, apontando os impactos positivos e negativos que resultarão pelo adensamento populacional informado no empreendimento Serra Shopping; a sobrecarga de equipamentos urbanos e comunitários; a geração de tráfego na área; demanda de transporte público; modificação da paisagem e impactos ao patrimônio natural no local da obra, bem como geração de resíduos líquidos e sólidos e sua destinação final; além do impacto à valorização imobiliária da área.

Em situação análoga, em uma decisão provida em 2015 pelo Ministério Público do Estado de Minas Gerais, no município de Água Comprida, onde o Poder Público municipal editou uma lei ampliando o perímetro urbano para propiciar a implantação de um Condomínio de alto padrão, houve impedimento a essa implantação, e no despacho discutiu-se que:

[...] as prefeituras, geralmente com apoio das Câmaras Municipais, vêm, historicamente, ampliando de forma casuística o perímetro urbano, com o propósito de favorecer a implantação de empreendimentos voltados à comercialização de ranchos e imóveis para lazer aquático. Nessa ampliação, os entes municipais simplesmente desconsideram as normas impostas pela legislação, seja o Estatuto das Cidades (Lei Federal 10.257/2001), seja a lei que dispõe sobre o parcelamento do solo urbano (Lei Federal 6.766/79), ou quaisquer outros diplomas legais aplicáveis ao caso, como o plano diretor. A transformação de uma área rural em urbana somente é possível se cumpridos uma série de requisitos previstos no Estatuto das Cidades, o que não tem sido observado nesses casos. E se não bastassem às violações de ordem urbanística, as prefeituras se abstêm de exigir licenciamento ambiental para esses empreendimentos e, inclusive, compactuam com a sua implementação em área de preservação permanente, que, além de proibida, resulta em danos ao ecossistema, como desmatamento, alteração do microclima da região e assoreamento dos cursos d'água.

A legislação que regulamenta esses empreendimentos dispõe-se na Lei Federal no 6.766/79 (Parcelamento do Solo Urbano), que se mostra obsoleta aos arranjos imobiliários atuais. Silveira (2010) enaltece que esses tipos de empreendimentos não existem juridicamente, apresentam um aparamento jurídico confuso. Ainda segundo Silveira (2010), os municípios não têm autonomia para autorizar essa forma de loteamento condominial; Lei municipal que preveja ou regule sua implantação contamina o ato de aprovação de flagrante ilegalidade, porque o Município não tem competência legislativa.

\section{CONCLUSÕES}

Ao se levar em consideração que os municípios de Areia e Bananeiras já apresentavam alto potencial turístico, pode-se compreender que esses empreendimentos têm como foco turistas investidores que aproveitam os finais de semana, feriados e períodos de férias para se refugiar em "residências secundarias", o que pode configurar conflitos territoriais devido à ocupação alóctone e privatização de bens públicos por grupos sociais específicos. 
A implantação desses empreendimentos é considerada potencialmente poluidora por suas implicações ambientais, ligada privatização de áreas públicas, como as margens do reservatório Saulo Maia em Areia, e poluidora, uma vez que a produção de resíduos sólidos, esgoto sanitário e outras composições pode acarretar danos ao manancial. Apesar de privativo em seu interior, com cobranças de taxas e impostos de uso dos serviços oferecidos, esses empreendimentos ao se instalarem necessitam da prestação de serviços públicos, como coleta de resíduos, transporte público, pavimentação e segurança de áreas adjacentes, e dessa forma, uma demanda de planejamento e recursos das prefeituras, o que pode ser tornar ilegal.

É necessário investigar se esses empreendimentos têm tipo influência sob o aumento expressivo da violência e êxodo rural dos municípios, o que compromete diretamente o setor primário, atuando na mudança de uso e função econômica de forma problemática a sociedade autóctone. Além da Lei de parcelamento do solo, os condomínios fechados estão alicerçados na Lei Federal no 4.591/1964. Entretanto, a conjuntura desses empreendimentos aflige diretamente a liberdade de circulação humana, e na situação em estudo, há uma privatização dos elementos da paisagem, como a água, assim como destruição das APPs. Assim, é importante analisar esses os impactos ambientais de forma jurídica, uma vez que a expansão apresenta um ritmo acerado.

\section{REFERÊNCIAS}

ALVES FILHO, M.. Os códigos invisíveis da convivência intramuros. Jornal da Unicamp, Campinas: 2001.

ARAUJO, D. C.; DINIZ, L. S.; MARQUES, A. L.. Novo rural brasileiro nos Brejos do Estado da Paraíba. Revista Geotemas, Natal, v.6, 2016.

ARAÚJO, D. C.; MARQUES, A. L.; NERI, U. D. B.; OLIVEIRA, J. D.; RAMOS, A. R. D.. Reservatório Saulo Maia, Areia-PB: uso da terra e conflitos hídricos. WORKSHOP INTERNACIONAL SOBRE ÁGUA NO SEMIÁRIDO BRASILEIRO, 2. Anais. Campina Grande, FIEP, 2015.

BECKER, D.. Capital Social: Uma nova derivação da economia de mercado?. In: Capital Social e desenvolvimento regional. Santa Cruz do Sul: EDUNISC, 2003.

BOTELHO, A.. 0 urbano em fragmentos: a produção do espaço e da moradia pelas práticas do setor imobiliário. São Paulo: Annablume, 2007.

BRASIL. Diretrizes para o Desenvolvimento do Turismo Rural no Brasil. Brasília: 2003.

CALDEIRA, T. P. R.. Cidade de muros: crime, segregação e cidadania em São Paulo. 2 ed. São Paulo: Edusp, 2000.
FRANCO, M. L. P. B.. Análise de conteúdo. 2 ed. Brasília: Liber Livro, 2005.

IBGE. Instituto Brasileiro De Geografia E Estatística. Portal IBGE Cidades: Areia-PB; Bananeiras-PB. Brasília: IBGE, 2015.

MARQUES, A. L.; SILVA, J. B.. Análise da Área de Preservação Permanente no entorno dos reservatórios artificiais de água do município de Areia-PB. In: WORKSHOP INTERNACIONAL SOBRE ÁGUA NO SEMIÁRIDO BRASILEIRO, 1. Anais. Campina Grande, FIEP, 2013.

MUKAI, T.. Direito Urbano-Ambiental brasileiro. São Paulo: Dialética, 2002.

NASSER, R. M.. As cidades e as "novíssimas guerras": a militarização do espaço urbano. In: 11 de setembro à guerra ao terror reflexões sobre o terrorismo no século XXI. Brasília: IPEA, 2014.

SANTOS, M. A. M.. Os condomínios fechados horizontais e as dinâmicas recentes da produção do espaço urbano: bairro Passaré em Fortaleza-CE. Dissertação (Mestrado acadêmico) - Universidade Estadual do Ceará, Fortaleza, 2015.

SANTOS, M. M. A.; TABARELI, M.. Uma Breve Descrição Sobre a História Natural dos Brejos 
Nordestinos. In: Brejos de altitude em Pernambuco e

Paraíba: história natural, ecologia e conservação.

Brasília: 2004.

SILVA, J. G.. O novo rural brasileiro. 2 ed. Campinas: UNICAMP, 1999.

SILVEIRA, P. F.. Condomínio fechado, associação de moradores e lei municipal. Brasília: 2010.

SOGAME. M.. Rudimentos para o exame da urbanização em sua fase crítica: uma aproximação ao conceito de segregação socioespacial. Geografares, Vitória, v.2, n. 2, 2001.

VASCONCELOS-SOBRINHO, J.. Os brejos de altitude e as matas serranas. In: As regiões naturais do Nordeste, o meio e a civilização. Recife: Condepe Fidem, 1971. 